\title{
Restauração da fotopintura "Retrato em tamanho natural de Santos Dumont", do fotógrafo Giovanni Sarracino*
}

\author{
Yara Lígia Mello Moreira Petrella \\ Museu Paulista da USP \\ Nazareth Coury \\ Centro de Conservação e Preservação Fotográfica - \\ CCPF/FUNARTE \\ Sônia Maria Spigolon \\ Museu Paulista da USP \\ Beatriz Carvalho Ricardo \\ Mago das Imagens
}

A Fotografia de Santos Dumont em tamanho natural e de corpo inteiro, de grandes dimensões, com $197 \mathrm{~cm}$ de altura por 75,50cm de largura, se destaca dentre as coleções fotográficas do Museu Paulista?. Trata-se de uma fotopintura, de 1904, que tem como características a ampliação em tamanho natural em gelatina e a utilização de retoque com traços finos, ressaltando atributos expressivos e fisionômicos, e de pintura em algumas áreas, para acentuar volumes através de sombreamento. A obra é o resultado de um processo fotográfico constituído por três camadas, sendo elas o papel, a barita (sulfato de bário que recobre o papel) e a emulsão fotogrática como meio ligante, que neste caso é a gelatina, onde os sais de prata ou haletos são dispersos, que sensibilizados ou expostos à luz formam a imagem fotográfica. $\bigcirc$ resultado final após o processamento é a prata metálica (FIGURA 1).

Seu autor é o fotógrafo Giovanni Sarracino, que assina no canto inferior esquerdo: "GSarracino, Rua 15 de novembro, São Paulo."2 A fotografia foi montada numa moldura de porte monumental. Assim podemos apresentála:

"Moldura constituída por peça de madeira (com emendas), na qual há ornamentos esculpidos em relevo, figurando um sentido geral do triunfo aeronáutico brasileiro e sul-americano de Alberto Santos Dumont, por meio dos seguintes motivos: na parte superior, presidindo o conjunto, um condor, pássaro de cujas características

\footnotetext{
*Além dos autores, participaram do trabalho de conservação e restauração os técnicos Marcos Antonio Steiner e Eloísa Floriano de Toledo. Este trabalho teve o apoio institucional do Centro de Conservação e Preservação Fotográfica da FUNARTE.

1. Número de registro da imagem no Serviço de Documentação Textual e Iconografia:IC 22823.

2.Giovanni Sarracino, nascido em Torre del Greco, na Itália, frequentou o Liceu de Artes e Ofícios e abriu seu próprio ateliê em São Paulo,na Rua Formosa, em 1901. Seus trabalhos estão publicados em várias revistas ilustradas. Além da Exposição Universal de Saint Louis, nos Estados Unidos, Sarracino participou da Exposição Nacional de 1908 com retratos de Albuquerque Lins, Jorge Tibiriçá,Washington Luiz, Olavo Egydio, Carlos Botelho,Siqueira Campos,
} 


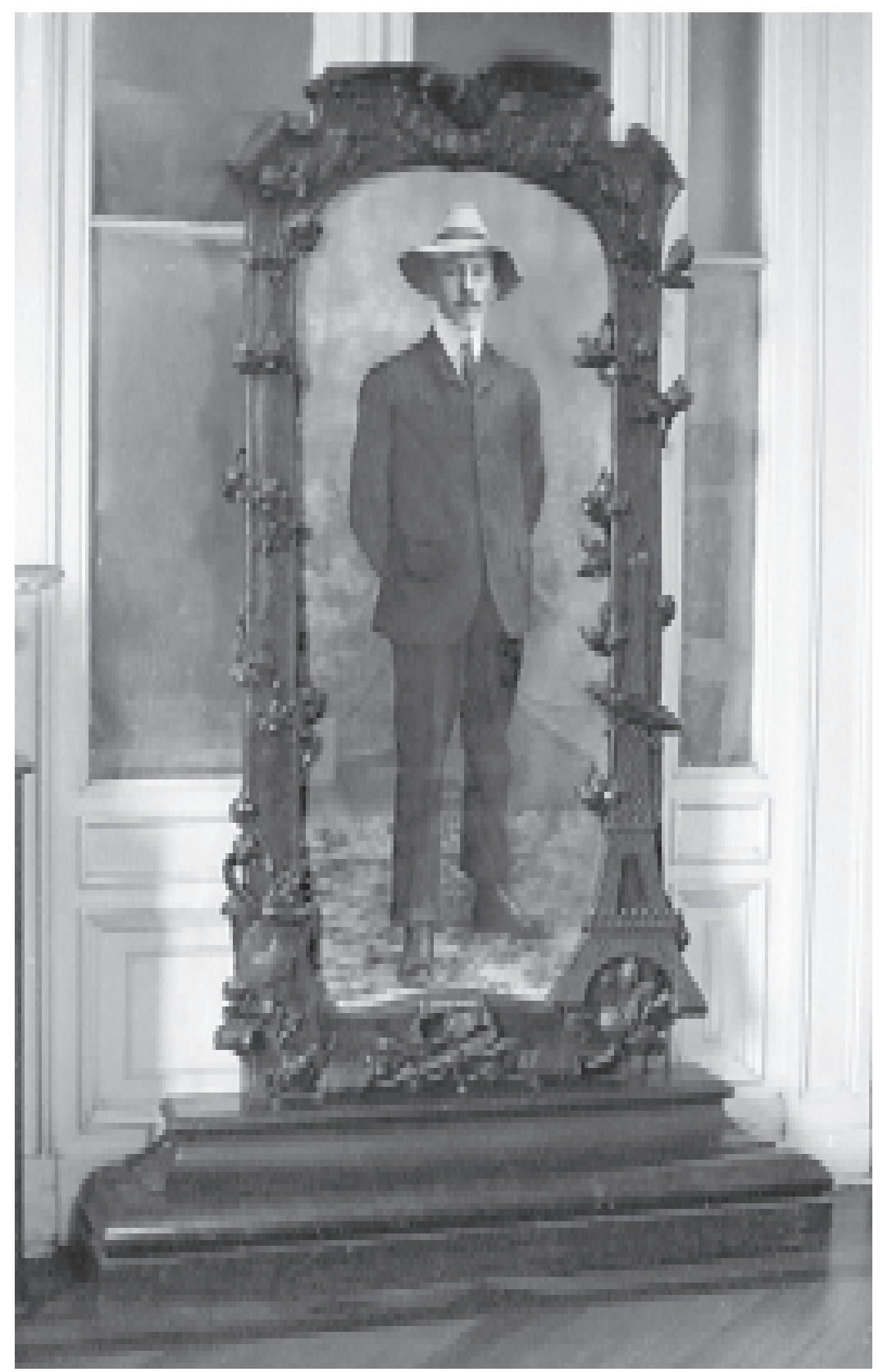

FIGURA 1 - Fotografia e moldura na exposição. Fotografia de José Rosael. 
normalmente se sublinham a força e a origem sul-americana (andina), em posição de vôo, sobre nuvem (houve perda do bico e de grande parte da asa à esquerda de quem olha). Ao longo de toda a lateral à esquerda de quem olha, em sentido ascendente, um ramo de carvalho, simbolizando força; ao longo de toda a lateral direita, também em sentido ascendente, um ramo de loureiro, simbolizando vitória, ambos amarrados entre si, na parte inferior, por um laço de fita. No canto inferior esquerdo, a estrela do brasão de armas da República do Brasil, e na lateral direita, em sua metade inferior, a Torre Eiffel, em torno da qual passa um balão dirigível, em alusão ao feito de Santos Dumont que, em 1901, circundou aquela torre com o Dirigível nำ 6. Na parte inferior da moldura, acima do laço de fita, uma plaqueta de madeira, fixada por dois pregos, com a inscrição 'SANTOS DUMONT', foi agregada à peça, provavelmente a posteriori. A moldura é fixada em suporte também de madeira, com base que dá sustentação a toda a peça, no reverso da qual se encontra, à direita de quem olha, etiqueta de papel colada com a seguinte inscrição: "FABRICADO / NO / Liceu de Artes e Oficios / DE / SÃO PAULO." Logo abaixo dele, um selo de consumo, também colado, sobre o qual estão carimbadas as inscrições: "LYCE[O] DE ARTES E OFICIOS / INDUSTRIA BRA[Z]ILEIRA", parcialmente ilegíveis. Indicam a instituição onde foi confeccionada a moldura para abrigar a fotopintura de Giovanni Sarracino, que retrata Santos Dumont, apresentada em 1904, em São Paulo, na exposição estadual preparatória para a exposição internacional de Saint Lovis/EUA, realizada no mesmo ano. Nesta última - a Lovisiana Purchase Exposition -, esta fotografia, com a referida moldura, foi exposta na seção de artes liberais do Brasil e obteve medalha de bronze no Grupo C (Artes Liberais), Classe 16 (Fotografia)". ${ }^{3}$

Imagens da obra exposta na seção de artes liberais podem ser apreciadas em cartões postais e na revista Kosmos do mesmo ano 4 .

Em 1935, Arnaldo e Jorge Dumont Villares, herdeiros de Santos Dumont, juntamente com seu cunhado Ricardo Severo, doaram ao Museu Paulista um conjunto de 1.670 documentos tridimensionais, iconográficos e textuais que pertenceram ao inventor ou foram produzidos em sua homenagem em 1936, sob a gestão de Affonso de Escragnole Taunay. Foi inaugurada no Museu Paulista a "Sala Santos Dumont", cujas obras e execução estiveram a cargo e a expensas da família, ressaltando-se que a confecção do mobiliário expositivo foi executada sob medida no Liceu de Artes e Ofícios de São Paulo, inclusive a moldura da fotopintura em questão ${ }^{5}$. Desde a sua doação em 1936, a fotografia ficou exposta na sala dedicada a Santos Dumont, sendo transferida, em 1994, para a exposição no mesmo edifício "Todo Chapéu Possui uma Cabeça".

A fotografia de Santos Dumont estava aderida ao suporte secundário em tecido de algodão, e as bordas do tecido fixadas com tachinhas em um chassi. O conjunto estava montado em sua grande moldura e com vidro de proteção, este em contato direto com a área de imagem. A fotografia foi removida de sua moldura original pelos técnicos do Museu, sendo em seguida higienizada e colocada numa caixa de madeira provisória, forrada com papel-filtro. A seguir, a imagem foi tensionada e presa com grampos metálicos pelas laterais do tecido do suporte de base. Observou-se que permaneceram as deformações, e as perdas da emulsão continuaram a ocorrer.

Após a remoção, a fotografia foi submetida a diagnóstico, realizado pela técnica convidada do Centro de Conservação e Preservação Fotográfica da Funarte, Rio de Janeiro, juntamente com a equipe do Museu. entre outros. Cf. Boris Kossoy,Dicionário bistórico-fotográfico brasileiro: fotógrafos e ofício da fotografia no Brasil (18331910). São Paulo: Instituto Moreira Salles, 2002.p. 286.

3. Descrição feita por Heloisa Barbuy para o catálogo do Serviço de Objetos do Museu Paulista (número de registro $R G$ 1645).

4. Ver cartão postal do SVDHICO do MP/USP, IC 23576 e revista Kosmos, Anno I, n. 8, agosto, 1904.

5. Ver Heloisa Barbuy (Coord.). Dossiê: coleção Santos Dumont. São Pau1o: Museu Paulista da USP, 2000 (ms), e também Affonso de E. Taunay. Guia da secção historica do Museu Paulista. São Paulo: Imprensa Official do Estado, 1937. p. 96. 
primeiro passo para toda a conservação ou restauração fotográfica é a identificação do processo fotográfico, através de microscópio óptico com um aumento de 30x. A partir deste dado, definem-se as intervenções adequadas às suas características materiais e ao conjunto de danos. Ocorreram algumas mudanças de procedimentos técnicos no decorrer dos trabalhos, em função das reações observadas nos testes, mas sem alterar os principais objetivos.

Segundo registro da instituição, sabe-se que a fotografia ficou exposta por quase seis décadas na "Sala Santos Dumont", um tempo excessivamente longo de exposição à luz em níveis inadequados, provocando danos acumulativos e irreversíveis que, entre outras coisas, alteraram a coloração da imagem fotográfica, originalmente em preto e branco. A fotografia não possuía nenhuma proteção adicional pelo verso, estando exposta diretamente aos polventes atmosféricos. Assim, o tecido adquiriu um tom marrom-escuro, bem diferente do estado inicial, devido à sujidade e oxidação das fibras.

As alternâncias de umidade relativa e temperatura, por sua vez, produziram nos diferentes materiais que compõem este conjunto - madeira (do chassi), tecido, cola, papel e emulsão fotográfica - uma alteração dimensional em decorrência do processo de dilatação e retração, agravando os problemas de deterioração. Tais danos resultaram na ondulação da superfície do papel fotográfico colado sobre o tecido e na deterioração da camada de barita e da emulsão fotográfica que, vistas através de uma lente de aumento, mostravam-se craqueladas em ambas as camadas. Como conseqüência ocorreram perdas consideráveis da emulsão fotográfica prejudicando muito a leitura da imagem. A coloração da fotografia, originalmente em preto e branco, tornou-se amarelecida pelo processo de oxidação da prata. Somente nas áreas protegidas pela moldura, a fotografia ainda guardava a sua coloração original.

Nas bordas do tecido havia perfurações causadas pela oxidação das tachinhas e pequenos rasgos. No suporte primário havia também pequenos rasgos e até mesmo perdas em algumas áreas. Entre o chassi e o tecido, como também entre o vidro e a fotografia, havia um grande acúmulo de poeira cuja ação higroscópica absorveu a umidade ambiente e a transmitiu por contato à fotografia. Tal processo causou, na lateral inferior, grandes manchas, fragilizando tanto as fibras do papel como a emulsão fotográfica (FIGURAS 2, 3).

Os principais objetivos a serem atingidos eram a estabilização da emulsão fotográfica, a remoção do tecido, a planificação - que proporcionaria estabilidade estrutural - a reintegração visual, a montagem em passe-partout e o acondicionamento adicional em caixa sob medida.

$\bigcirc$ tecido, bastante deteriorado, juntamente com o adesivo, em toda a área central da fotografia, não cumpria mais sua provável função - a de fixar o papel fotográfico ao chassi e mantê-lo estirado. $\bigcirc$ tecido das bordas, embora em melhor estado porque ficou protegido da luz, apresentava perfurações causadas pela oxidação das tachinhas, o que não permitia mais uma fixação adequada ao chassi.

No primeiro teste, encontrou-se dificuldade para uma remoção mecânica do tecido com o uso do bisturi, pois as fibras se rompiam em pedaços e arrastavam consigo o papel do suporte fotográfico, fragilizando-o ainda mais. No segundo teste, aplicou-se umidade, o que também foi imediatamente descartado, porque o papel fotográfico, muito ressecado, se deformava rapidamente ao receber umidade. Portanto, tal procedimento, além de ser uma operação de risco, não contribuía em nada para a remoção do tecido. 


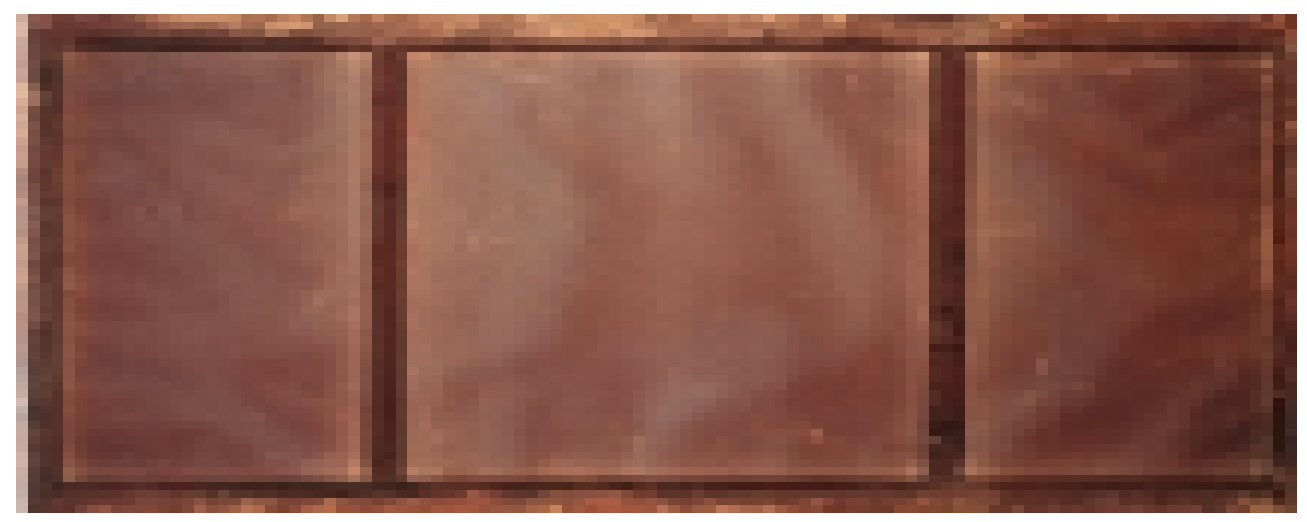

FIGURA 2 - Verso da fotografia, suporte em tecido fixado no chassi. Tecido com coloração marrom escura e deformações. Fotografia de José Rosael.

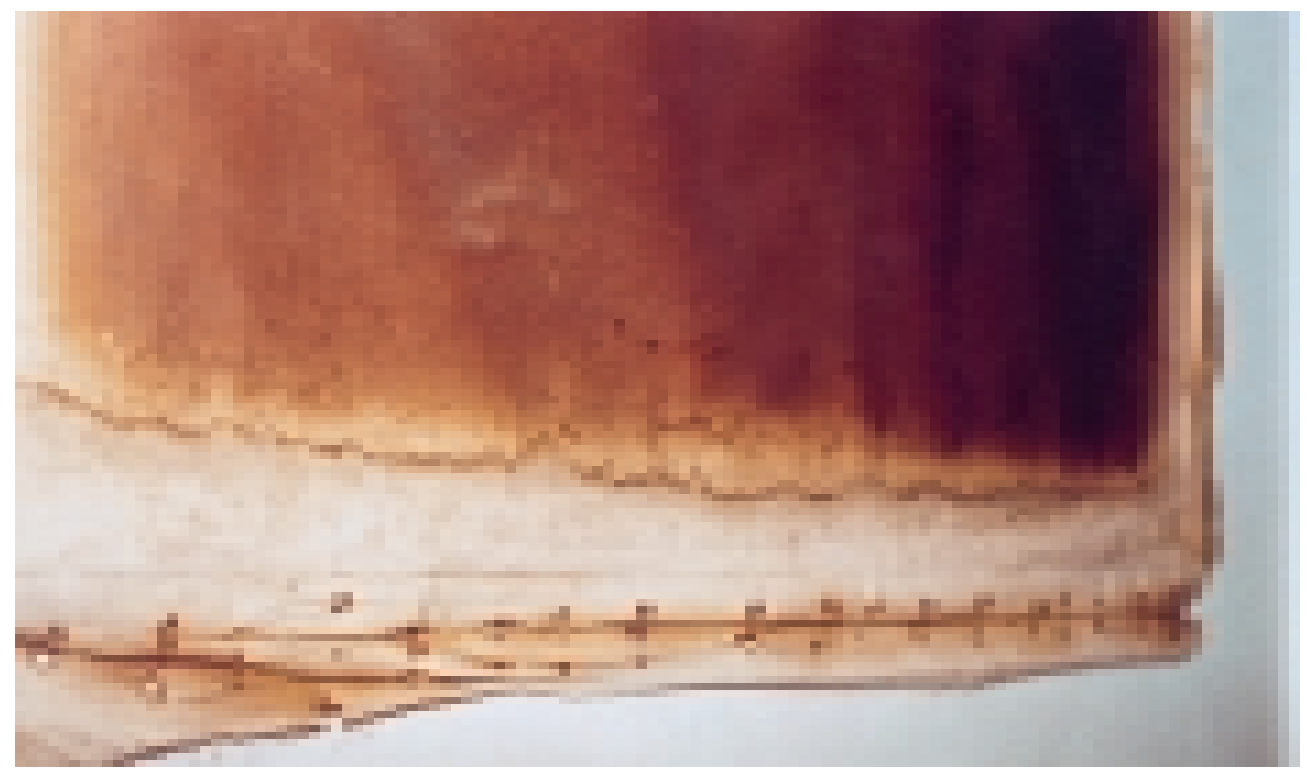

FIGURA 3 - Verso da fotografia, lateral inferior, sem o chassi. Manchas de umidade, bordas fragilizadas por furos das tachinhas e coloração mais clara do tecido situando-se sob o chassi, protegido da luz. Fotografia de José Rosael. 
Por fim, adotou-se a aplicação de metilcelulose a 4\%, em pequenas áreas de aproximadamente 15 a $20 \mathrm{~cm}$, durante dois minutos, para solubilizar o adesivo e desprender o tecido. $\bigcirc$ suporte secundário então se desprendeu com maior facilidade e segurança. A aplicação de umidade foi assim diminuída, mas em alguns pontos houve ainda o rompimento da camada do suporte. Logo após a remoção do tecido foram colocados pesos de mármore sobre placas de vidro, entretela e papel mata-borrão, para ajudar na secagem e planificação da área. Mesmo com esses cuidados, observou-se a ondulação em algumas regiões, principalmente nos limites da intervenção. Consideramos esta etapa de tratamento uma operação delicada e de muito risco. Durante este processo realizou-se a medição do $\mathrm{pH}$ de superfície com fita: $\mathrm{pH}$. 4,0 no centro da fotografia sobre o tecido, pH 5,O nas laterais; e sobre o centro do suporte e laterais pH 5,O (FIGURAS $4,5)$.

Durante a etapa do diagnóstico, testes foram realizados para verificar a melhor forma de consolidação da emulsão fotográfica, que se encontrava bem fragilizada. Esta consolidação foi o ponto mais crítico do tratamento. Utilizou-se metil-celulose bem diluída numa área de imagem, lateral inferior, e verificou-se que não houve marcas das pinceladas, sendo o resultado para a fixação da emulsão muito bom. Mas, por outro lado, não foi possível segurar as ondulações do papel fotográfico, apesar dos pesos, causando outros problemas mais sérios. Este procedimento foi, então, descartado (FIGURA 6).

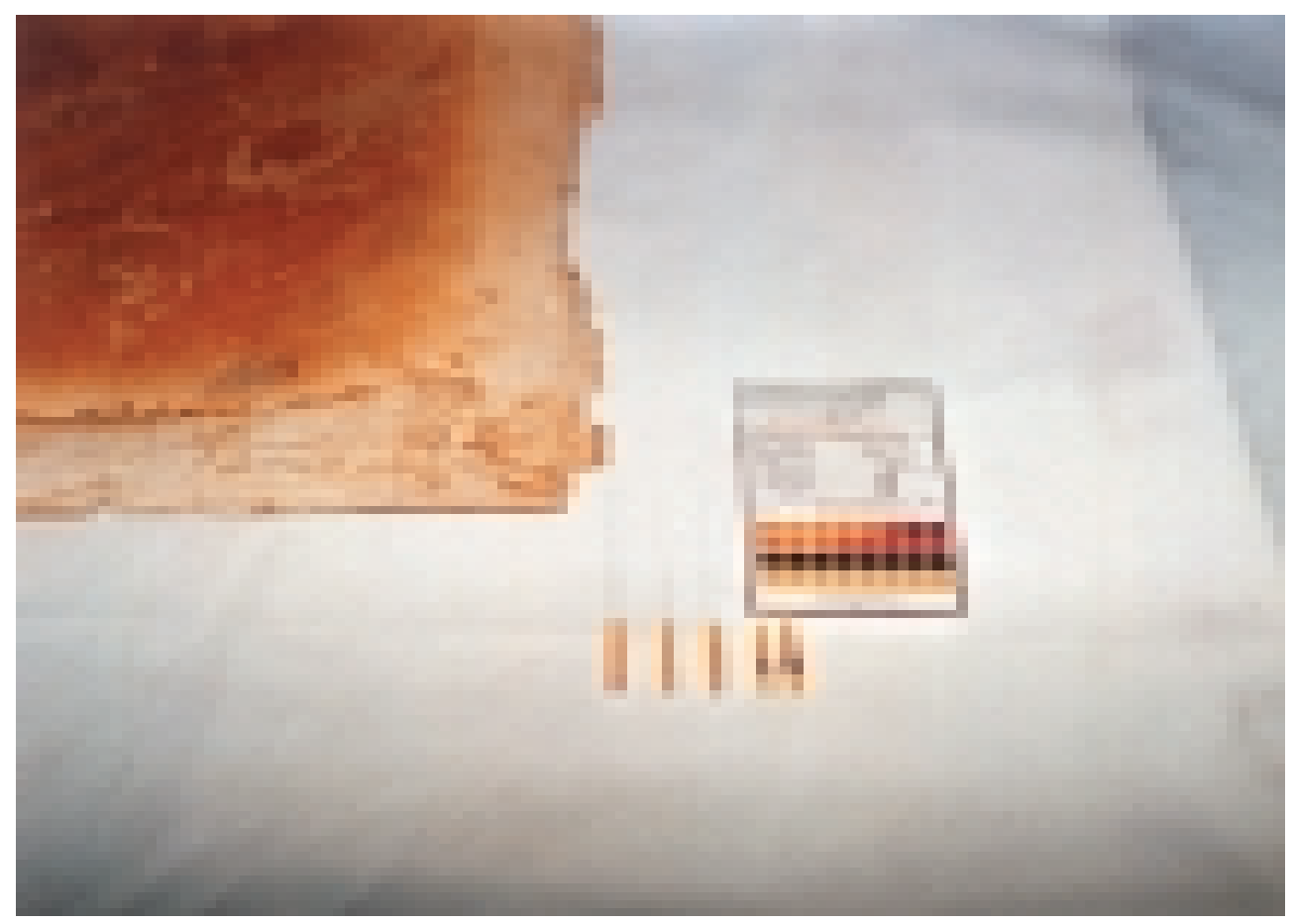

FIGURA 4 - Medição do pH. Fotografia de José Rosael. 


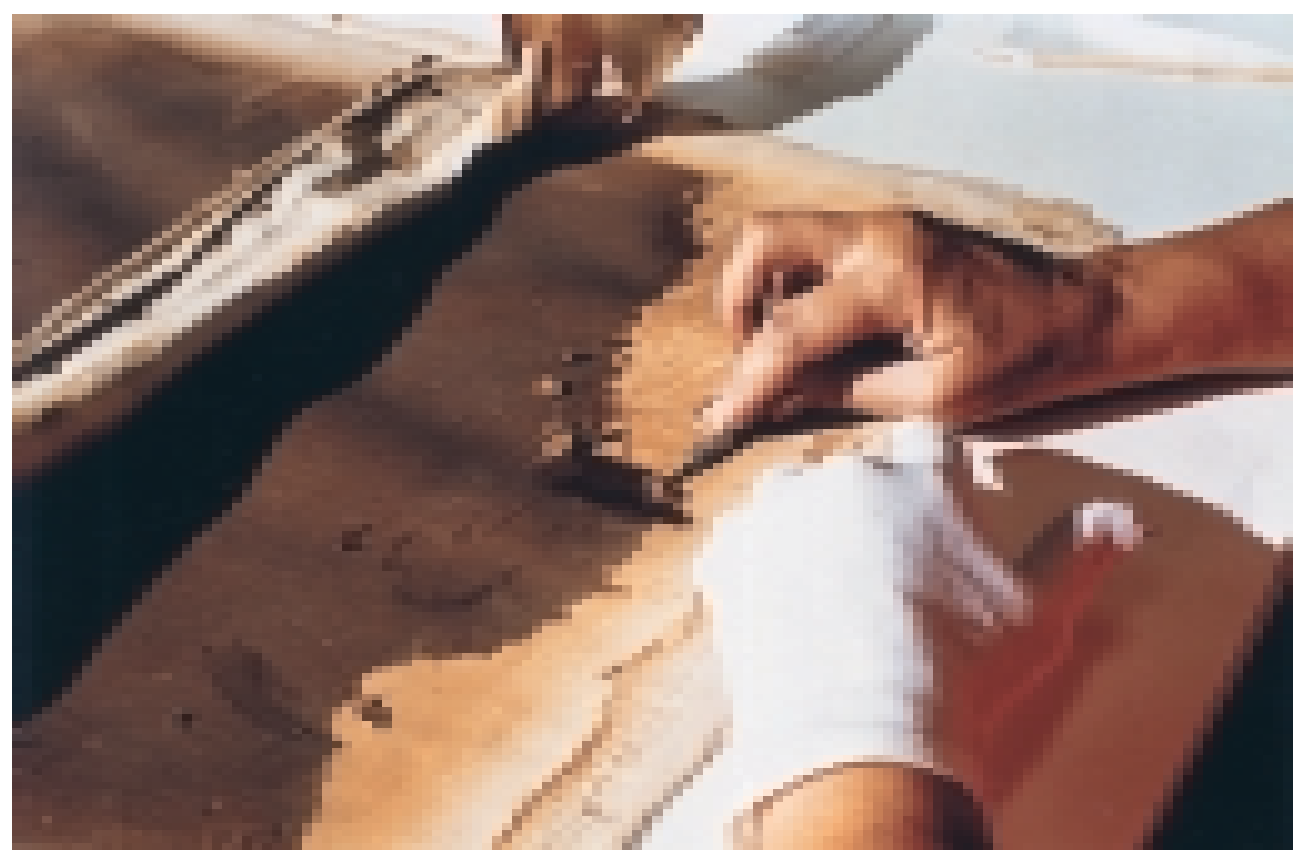

FIGURA 5 - Remoção do tecido. Fotografia de José Rosael.

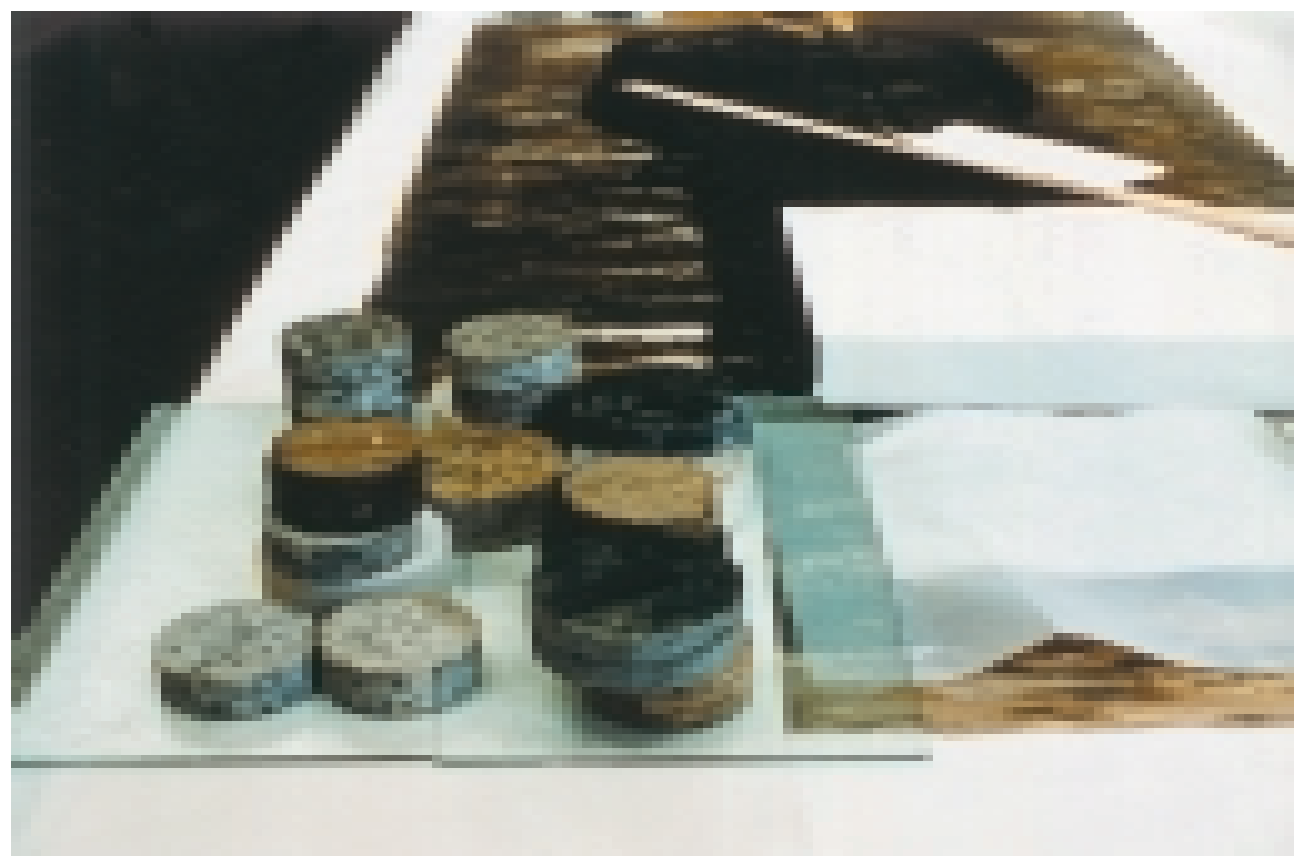

FIGURA 6 - Teste de consolidação da emulsão e a utilização de pesos. Fotografia de José Rosael. 
Após os resultados inadequados da consolidação preliminar, optou-se pela velatura para estabilizar estruturalmente o suporte e ao mesmo tempo fixar a emulsão pelo verso com maior segurança. Felizmente, o papel fołográfico, por ser bem espesso, contribuiu para dar maior segurança à execução do tratamento de estabilização. Este foi o melhor caminho escolhido e com bons resultados obtidos. Neste trabalho, foi utilizado papel japonês de gramatura adequada à espessura e dimensões do original e como adesivo metil-celulose e cola de amido em proporções iguais.

A fotografia foi preparada para a velatura trabalhando-se bem o verso, isto é, removendo-se todos os resíduos de tecido, o que incluiu a aplicação de lixa 360 nas áreas onde havia concentração do adesivo original. Nivelou-se, assim, muito bem o verso do suporte fotográfico.

As áreas com rasgos e perfurações receberam pequenos remendos em papel japonês de baixa gramatura, um procedimento adotado para proteger a emulsão fotográfica e impedir que o adesivo se transfira para a área de imagem.

Preliminarmente à velatura, a fotografia passou por um relaxamento das fibras do papel através da utilização de umidade controlada, repousando-a sobre folhas úmidas de papel mata-borrão. O papel japonês Okawara de $60 \mathrm{~g} /$ m2 natural foi utilizado em duas partes, sendo uma de $99 \times 183 \mathrm{~cm}$ e outra de 66 $X 96 \mathrm{~cm}$. As laterais destas duas folhas foram rompidas com umidade, para que não houvesse relevo nas emendas. Este papel foi totalmente molhado com água deionizada e esticado com trincha de cerdas macias sobre uma mesa de fórmica. Antes da aplicação do adesivo, retirou-se o excesso de água com folhas de papel mata-borrão. O adesivo, preparado com 50\% de metil-celulose e 50\% de amido de $\mathrm{pH} 8,0$, e mais a água suficiente para produzir uma massa densa, resultou numa cola com pH 7,0. $\bigcirc$ adesivo foi aplicado uniformemente com trincha sobre o papel japonês. À parte, reservaram-se telas de nylon para ajudar na planificação da fotografia e remover as bolhas eventualmente formadas na superfície.

A fotografia foi pousada aos poucos sobre o papel japonês. Com luvas de helanca, iniciou-se a colocação pela lateral superior, pressionando-se a tela de nylon com espátula de teflon macia. Esta operação difícil, de risco, delicada e ao mesmo tempo executada num curto espaço de tempo, exigiv a presença de três técnicos. Várias bolhas se formaram durante a realização da velatura, mas foram removidas imediatamente com a pressão de uma espátula até a primeira etapa de secagem do adesivo e dos papéis, durante uma hora e meia. Para acelerar a secagem, foram utilizados dois ventiladores (FIGURAS 7-12).

Ainda com a fotografia úmida, foram iniciados os enxertos nas áreas de perdas do suporte original. Os moldes de seus formatos foram extraídos com o emprego de poliéster Mylar. Foram executados 11 enxertos utilizando-se papel artesanal de polpa da mesma espessura do papel fotográfico. As perfurações foram preenchidas com polpa de papel e adesivo em 26 pontos. Assim, concluiuse a reintegração do suporte fotográfico (FIGURA 13).

A reintegração visual foi uma intervenção discutida entre as partes e caracterizou-se como uma exceção em relação ao tratamento usualmente aplicado ao acervo fotográfico do Museu Paulista. Considerou-se o fato da peça ser única, de grandes dimensões, feita nos moldes de uma pintura. Nessa escala, as perdas de emulsão fotográfica tornavam a sua leitura muito prejudicada. Reconheceu-se, portanto, a necessidade de diminuir as extensas lacunas brancas, com grande 


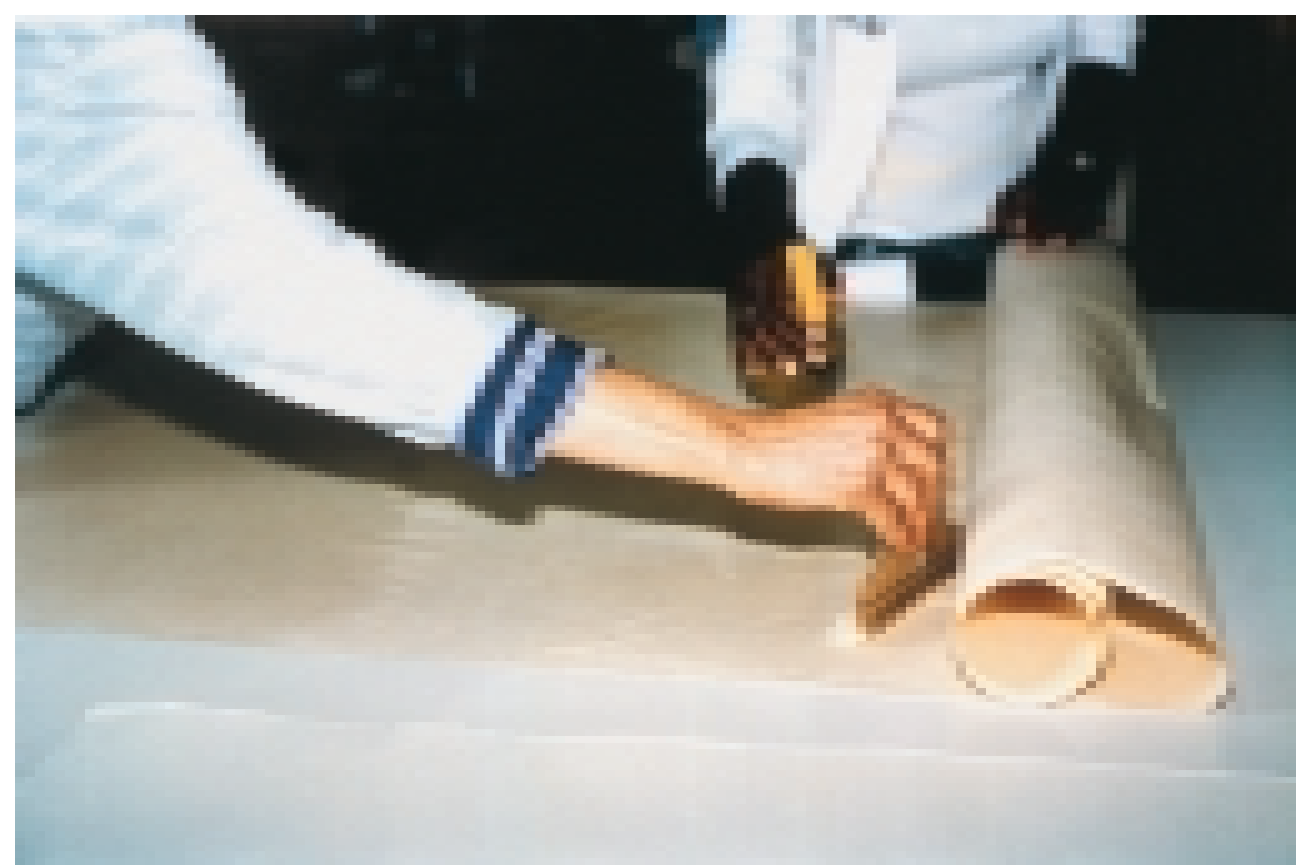

FIGURA 7 - Aplicação de umidade para planificação do papel japonês empregado na velatura. Fotografia de José Rosael.

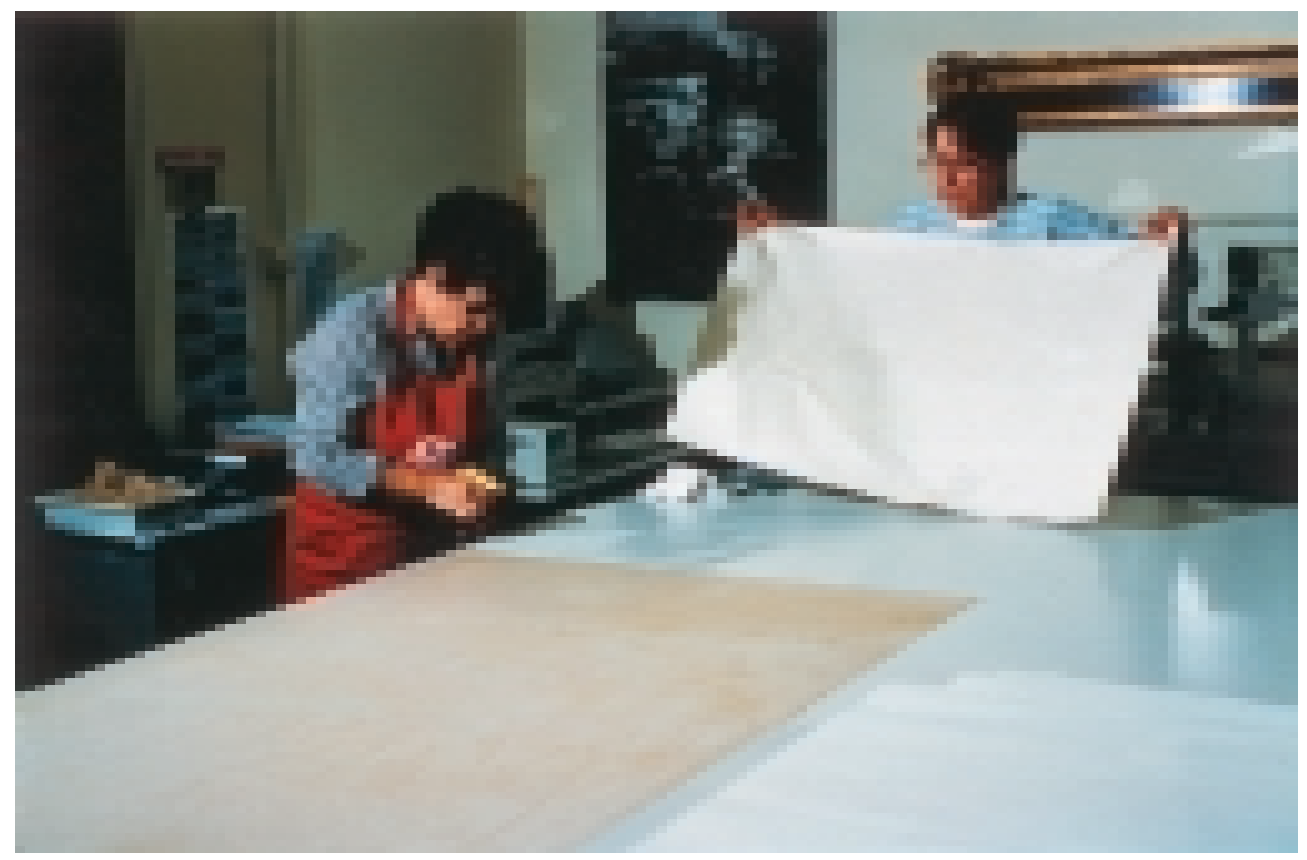

FIGURA 8 - Preparação e execução da emenda do papel japonês. Fotografia de José Rosael. 


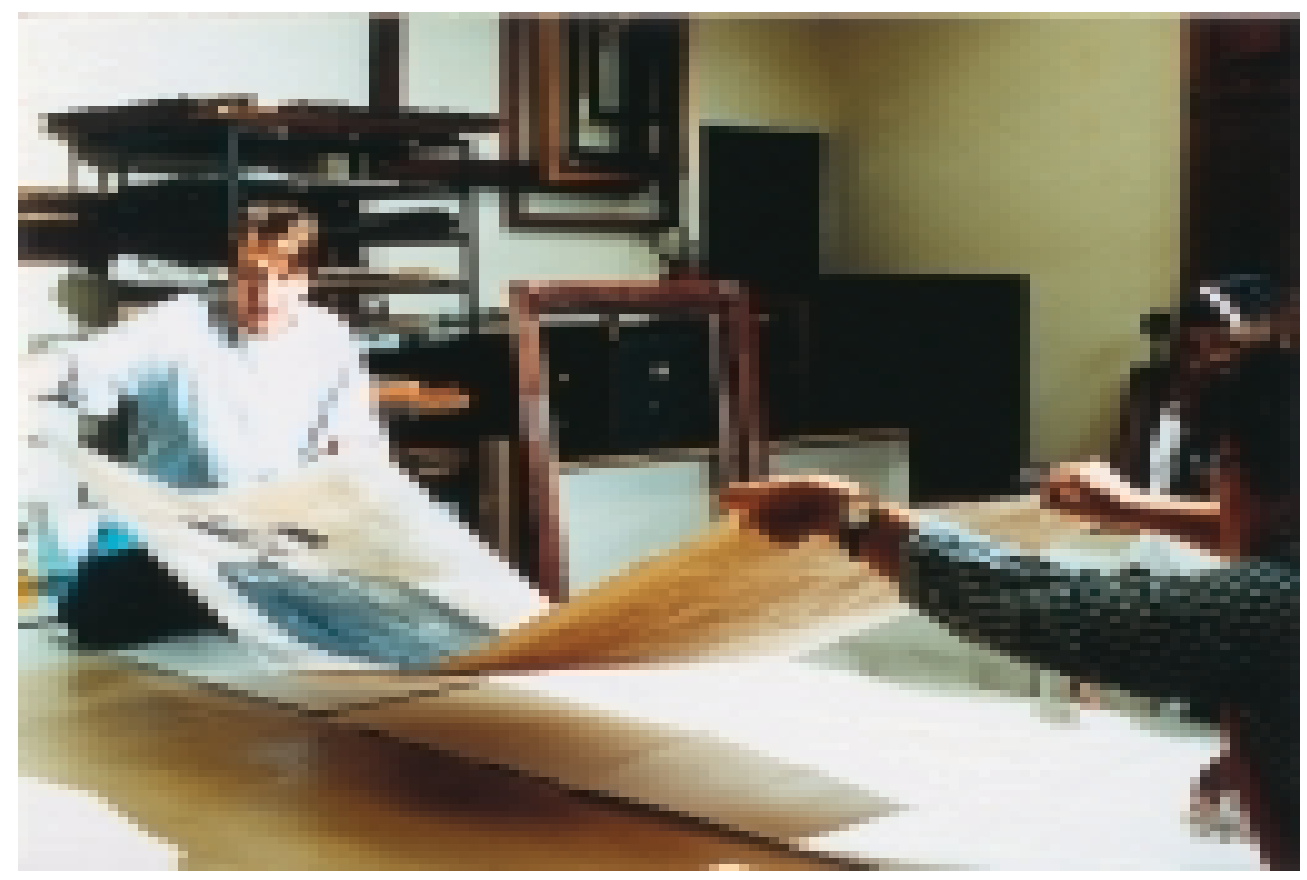

FIGURA 9 - Papel japonês com o adesivo aplicado e a fotografia sendo transportada. Fotografia de José Rosael.

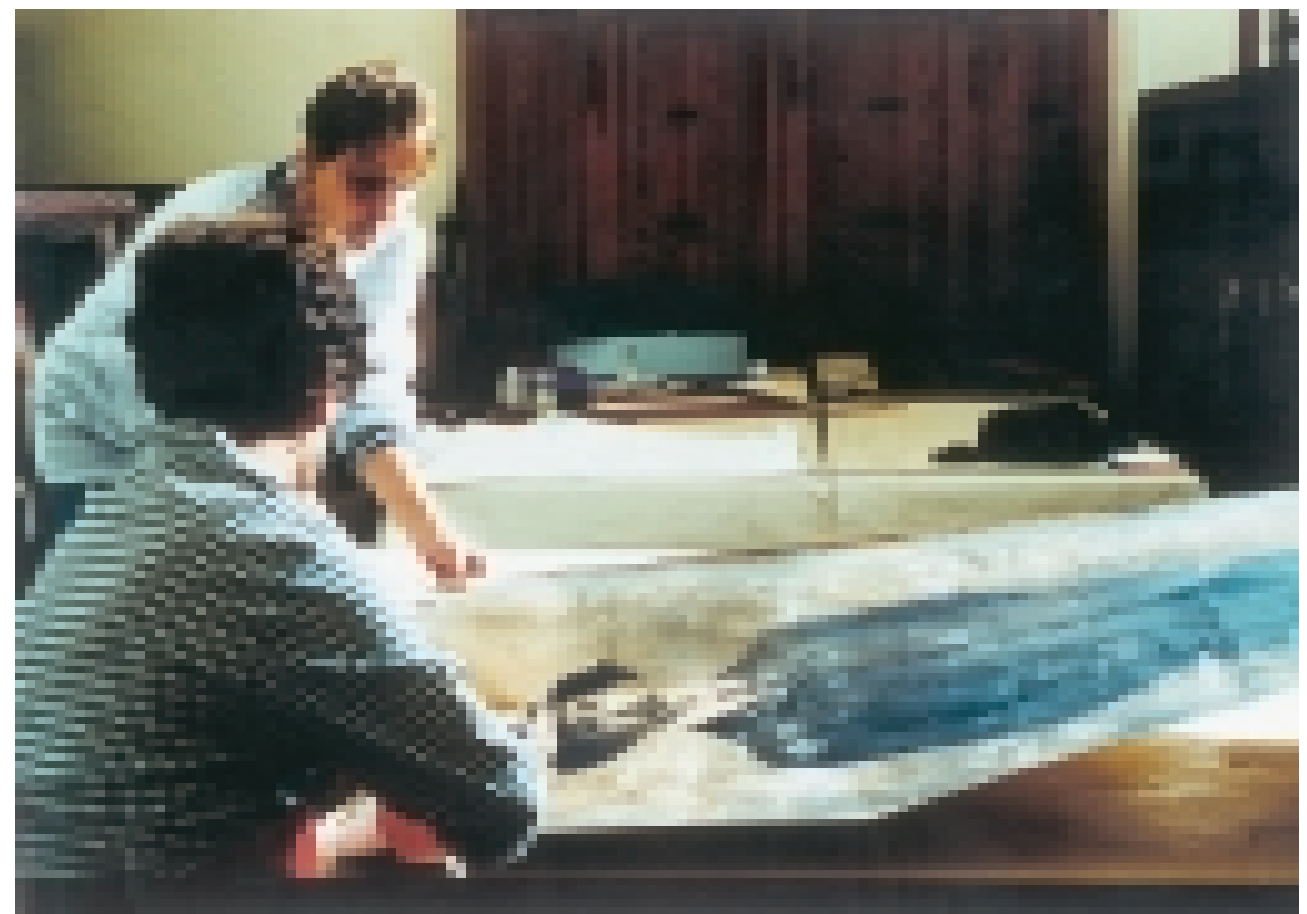

FIGURA 10 - Fotografia sendo pousada aos poucos iniciando-se o tratamento pela lateral superior. Fotografia de José Rosael. 


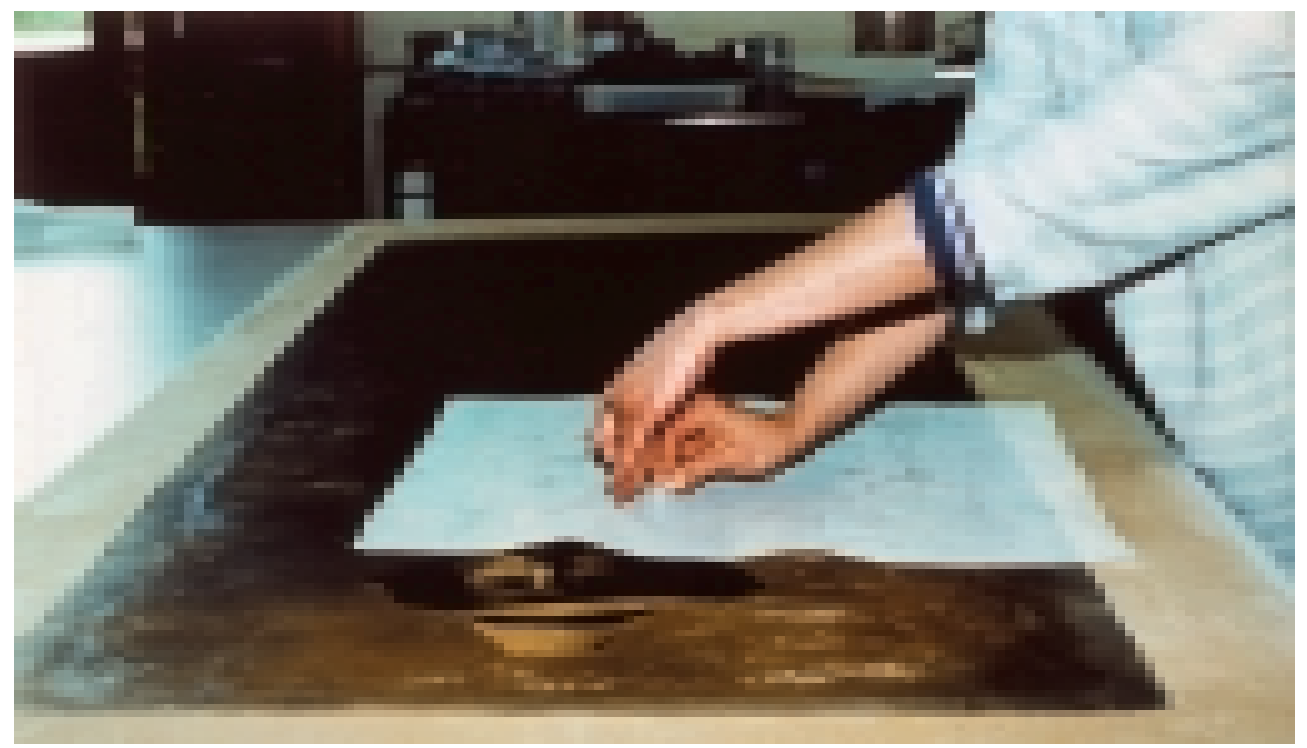

FIGURA 11 - Remoção de bolhas formadas no processo da velatura. Fotografia de José Rosael.

reflexão de luz, recuperando-se, pelo menos em parte, a leitura da obra original através de uma harmonização visual. Sabe-se que o retoque de fotografia é uma técnica de difícil execução e que apresenta limites nos resultados visuais e estéticos. Entretanto, o resultado final foi satisfatório.

Nas áreas de maiores perdas de emulsão fotográfica, durante o processo da reintegração visual, foi aplicada gelatina diluída para garantir maior estabilização e facilidade no retoque. O material empregado no retoque foi a aquarela Winsor \& Newton nas cores: White, Ivory Black, Sépia, Ocre e Yellow Naples, e a técnica adotada foi aquela conhecida como pontilhismo (FIGURAS 14-17).

Após concluída esta etapa de estabilização, iniciou-se outra fase do tratamento - a preparação do acondicionamento e da embalagem. A fotografia foi colocada sobre uma placa de display board, com acabamento em papel neutro e sem emendas, sendo suas dimensões maiores do que as da fotografia. A fotografia foi fixada neste suporte através de fita dupla-face aplicada nas bordas de sobra do papel japonês da velatura, deixadas para este fim. Sobre as bordas do display board e estreita faixa da fotografia foi colocado passe-partout em Crescent neutro king size, fixado na lateral esquerda com fita Filmoplast T, o que permitia o movimento e a visualização de toda a área da fotografia. $\bigcirc$ passepartout precisou ser emendado, o que foi feito com um corte inclinado e único, com fita auto-adesiva Filmoplast T branca.

Como embalagem adicional confeccinou-se uma caixa em display duplo nas áreas horizontais e triplo nas laterais verticais. Externamente a caixa foi revestida com francônia azul. Como adesivo foi utilizada cola PVA neutra. A fotografia, restaurada e protegida na embalagem, permanece no SVDHICO - Serviço de Documentação Histórica e lconografia (FIGURAS 18-21). 


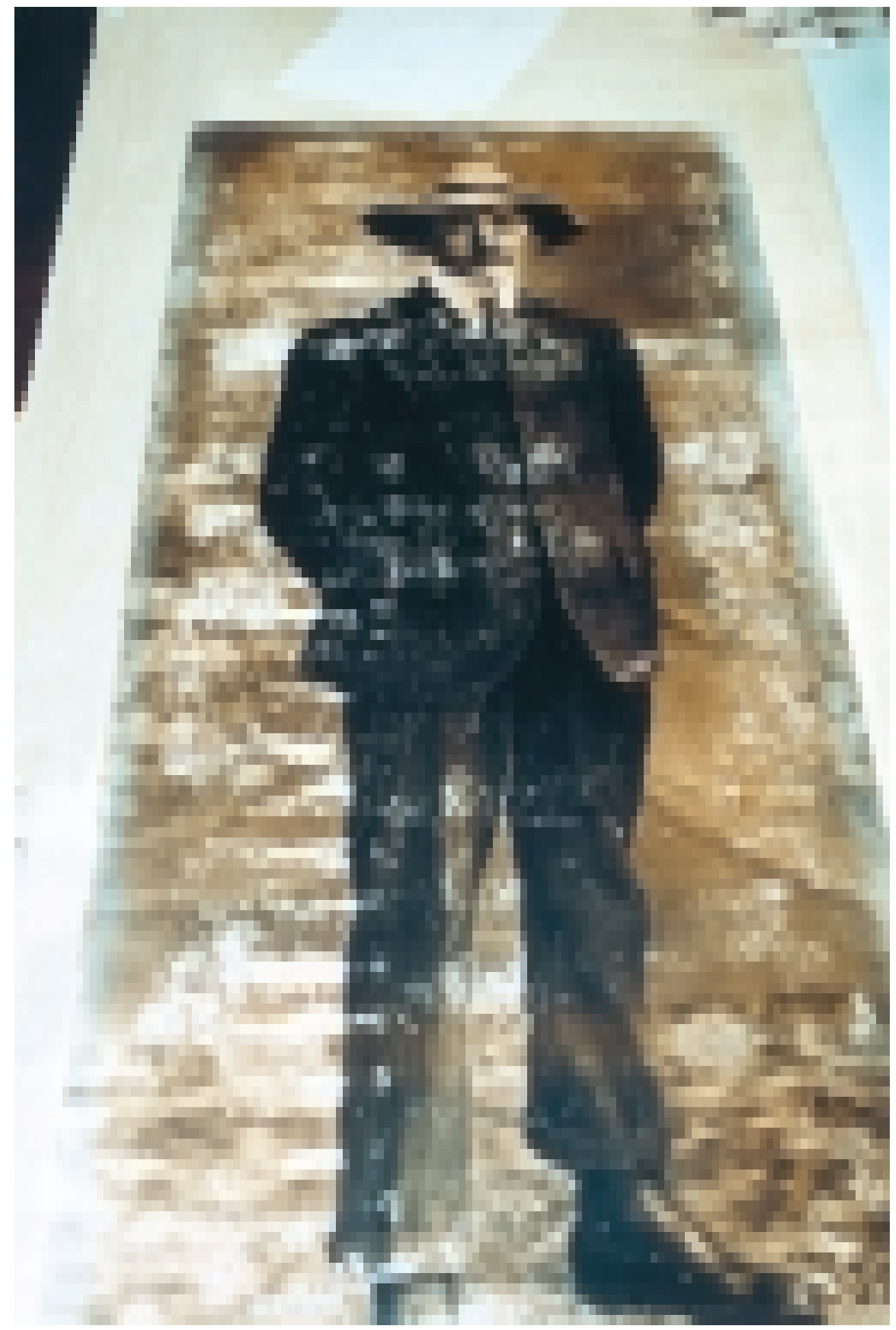

FIGURA 12 - Fotografia com a velatura executada e estabilizada estruturalmente. Perdas da emulsão fotográfica. Nas laterais direita e esquerda, faixa protegida pela moldura, apresentando sua coloração original. Fotografia de José Rosael. 


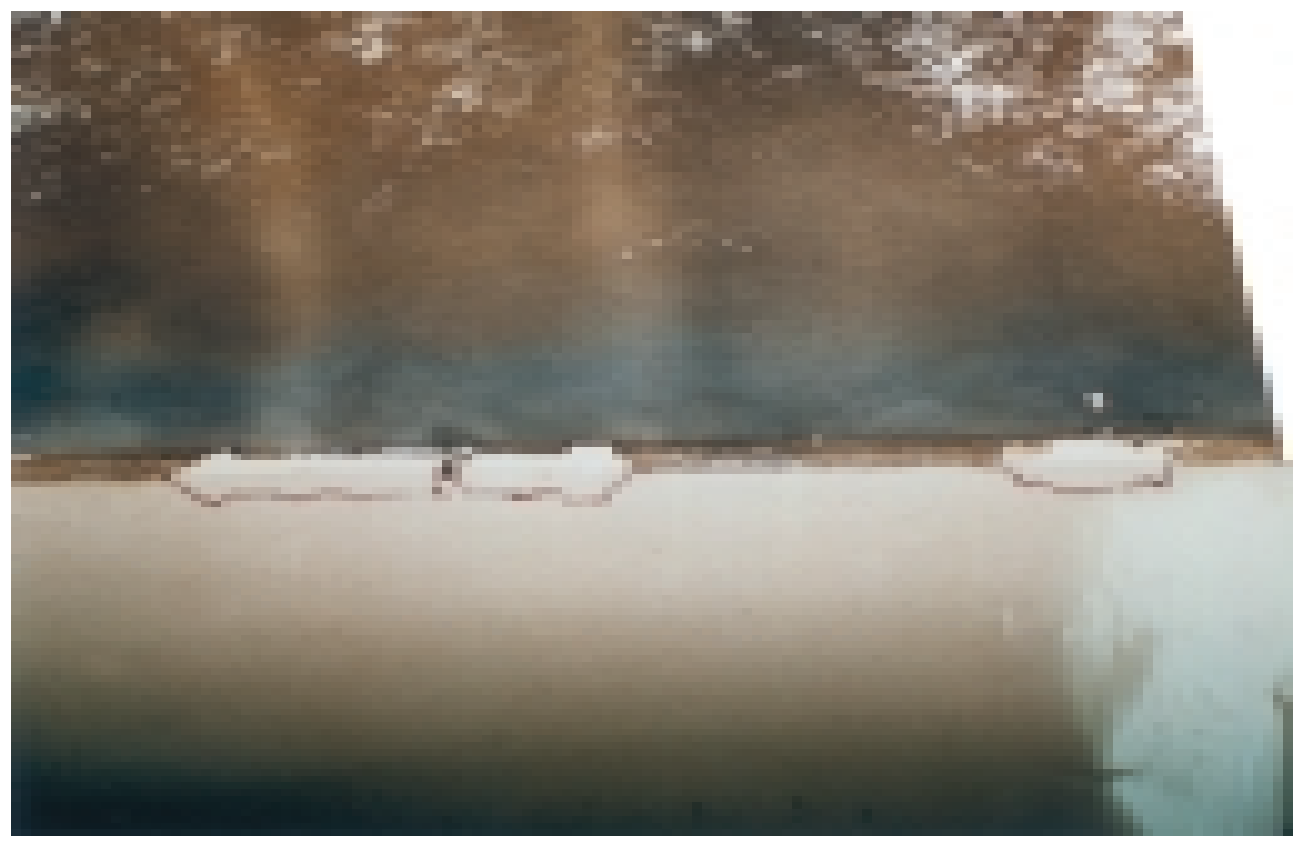

FIGURA 13 - Execução de enxerto nas laterais com papel artesanal. Fotografia de José Rosael.

Como mais uma etapa da preservação, foi gerado um cromo 4 X5. Uma vez obtido o cromo, este foi digitalizado em alta resolução possibilitando a recuperação digital. Através de software de manipulação de imagem, o Adobe Photoshop 7.0, utilizaram-se como ferramentas de trabalho o zoom e o pincel eletrônico, que permitiram chegar a detalhes da imagem impossíveis para o olho nu e o pincel convencional.

A fotografia analógica, isto é, a original, é um resultado mecânicofísico-químico e com processos de envelhecimento e de danos específicos. A fotografia digital, por sua vez, é um arquivo eletrônico, resultado da varredura de um escâner, que através de um CCD captura a luz refletida da peça fotográfica e a transforma em bits, ou seja, em dígitos, em pontos, que na tela do computador são chamados de pixels. Conhecidos também como "tijolos" da imagem, os pixels trazem consigo informações de cor e luminosidade.

Um conjunto de pixels pode ser movido de uma região para outra. Pode-se, então, substituir, através da sobreposição, uma região danificada por outras informações semelhantes mas que não sofreram danos. Os danos - como rasgos, perda de emulsão, manchas de umidade e fungos, vincos, sujidade, oxidação - na imagem digital deixam de ser danos estruturais, físicos ou químicos, para ser apenas problemas cromáticos relativos à recuperação da cor e luminosidade do pixel.

retoque convencional atingiu uma neutralização dos contrastes visuais. A recuperação digital vai além, chegando a informações mais completas sobre o que foi o original. Durante o processo de recuperação digital do retrato de Santos Dumont, graças à alta resolução da imagem e ao zoom, constatou-se que aquilo 


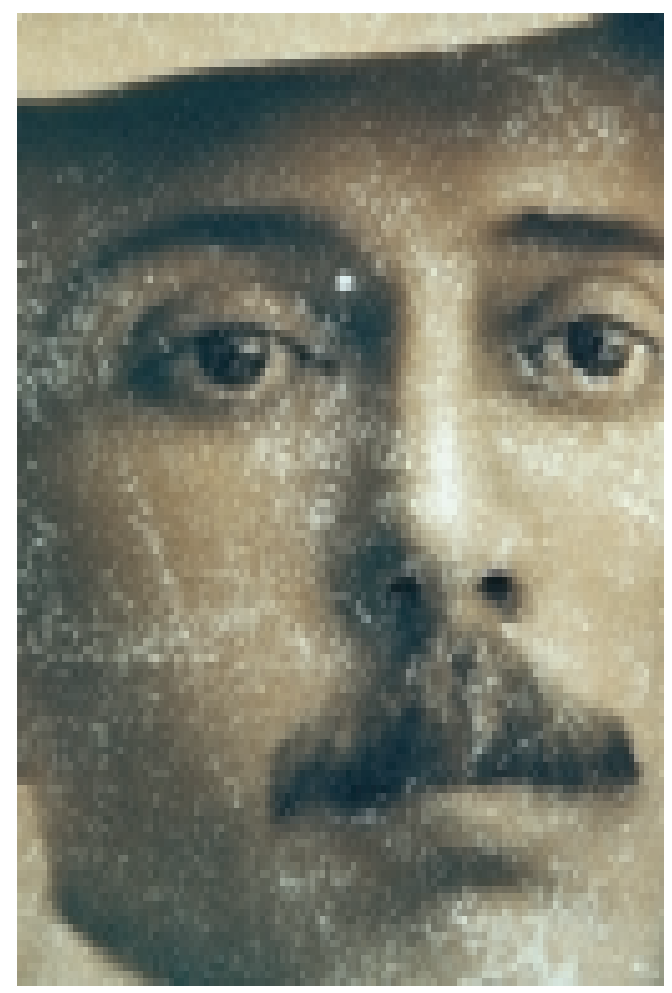

FIGURA 14 - Detalhe de perdas da emulsão. Fotografia de José Rosael.

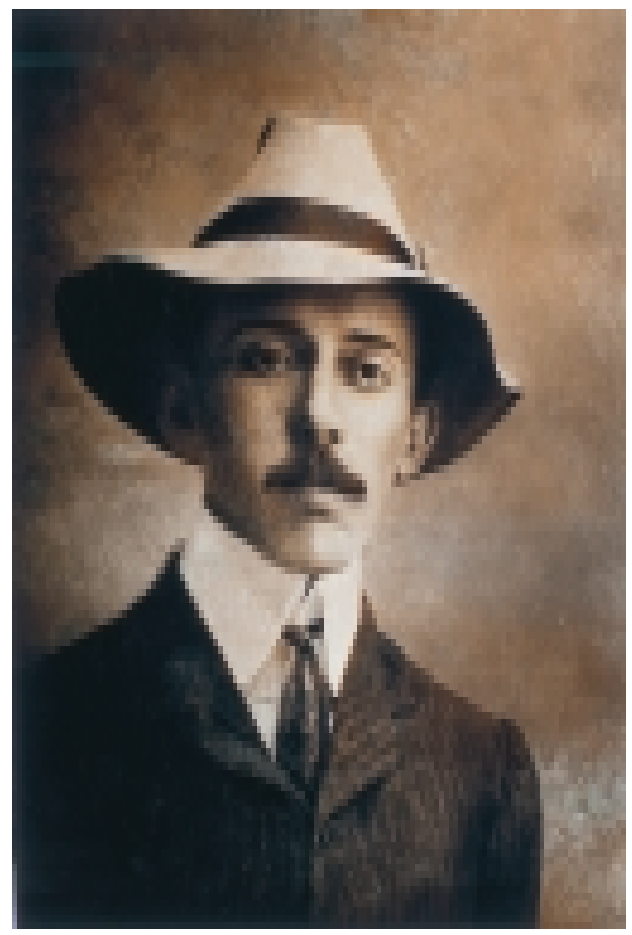




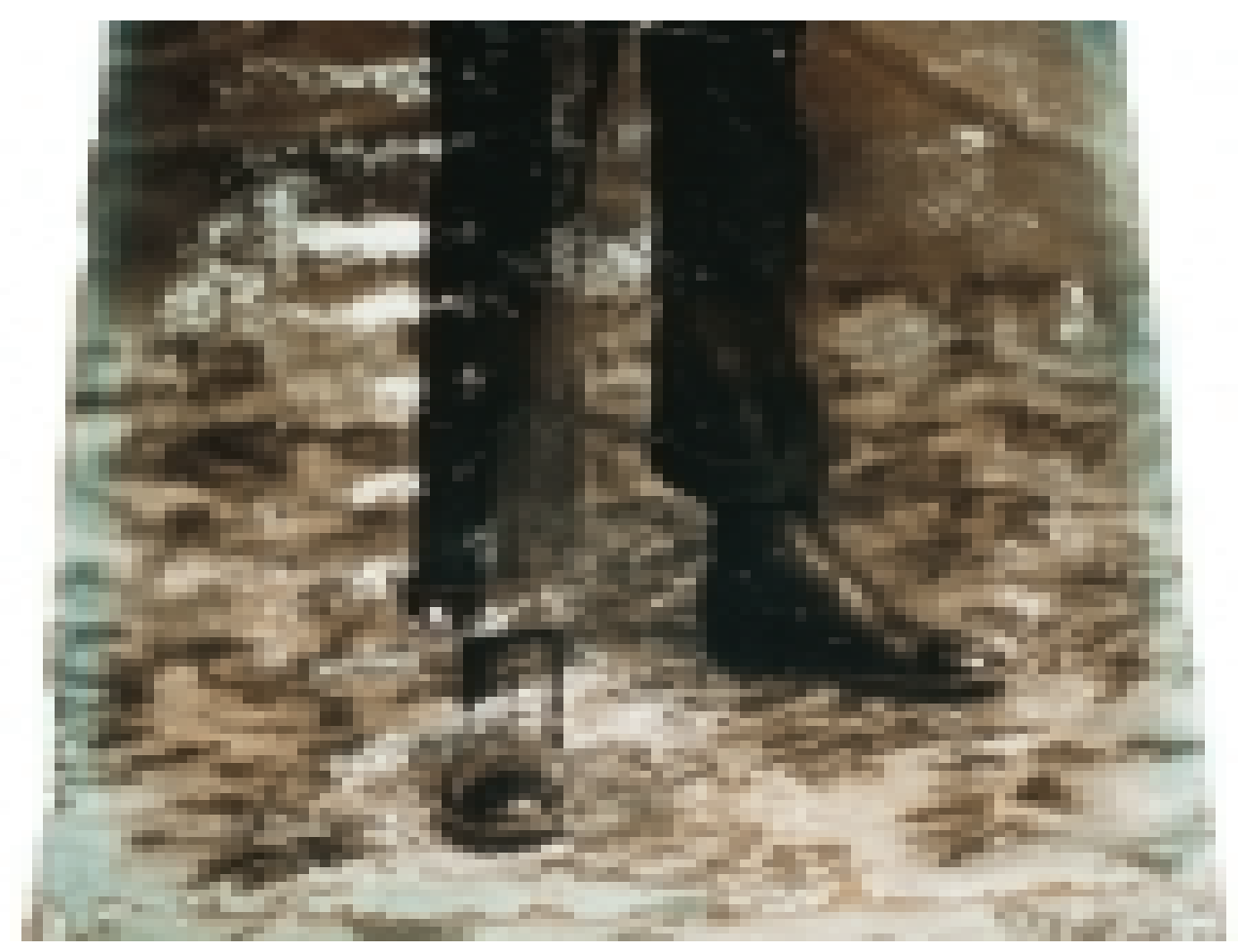

FIGURA 16 - Detalhe - área inferior das perdas da emulsão fotográfica. Fotografia de José Rosael.

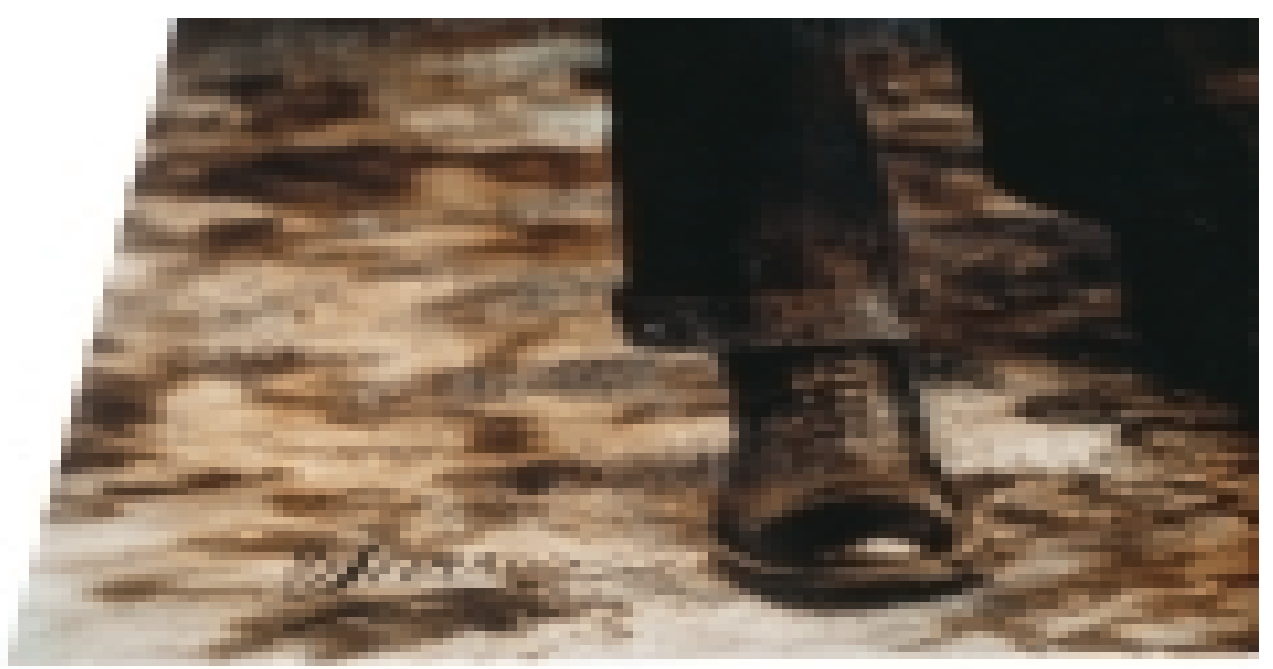

FIGURA 17 - Detalhe após execução de retoque. Fotografia de José Rosael. 
que parecia manchas de fungos era, na verdade, um motivo floral coerente, sobre o pano de fundo do cenário do ateliê. Os vestígios das flores no original fotográfico davam a ilusão de simples manchas. Dobras do tecido, também do cenário, estavam muito danificadas e perderam informações, e assim não fazia sentido formal e plástico. Mais uma vez, recuperou-se sua forma e volume. $\bigcirc$ tecido do terno tomou vida, pois a textura, os sombreamentos, o volume foram restabelecidos. A imagem original foi redescoberta. $\bigcirc$ arquivo da imagem recuperada permite saídas digitais em papel fotográfico quantas vezes se fizerem necessárias.

Deste modo, o Museu preserva seu original e volta a expor a reprodução digitalizada, disponibilizando ao público uma imagem satisfatória, mas guardando as características tonais semelhantes de seu envelhecimento, como se encontra hoje (FIGURA 22).

\section{Conclusão}

Pode-se considerar esta intervenção de restauração um desafio na área de conservação fotográfica. A grande dimensão da fotografia nos impôs um trabalho diferenciado, com soluções estruturais específicas.

No caso de uma fotografia em pequena dimensão e com danos semelhantes na imagem, a proposta de intervenção seria apenas uma conservação e a embalagem apropriada, permitindo-se sua consulta e guarda com segurança.

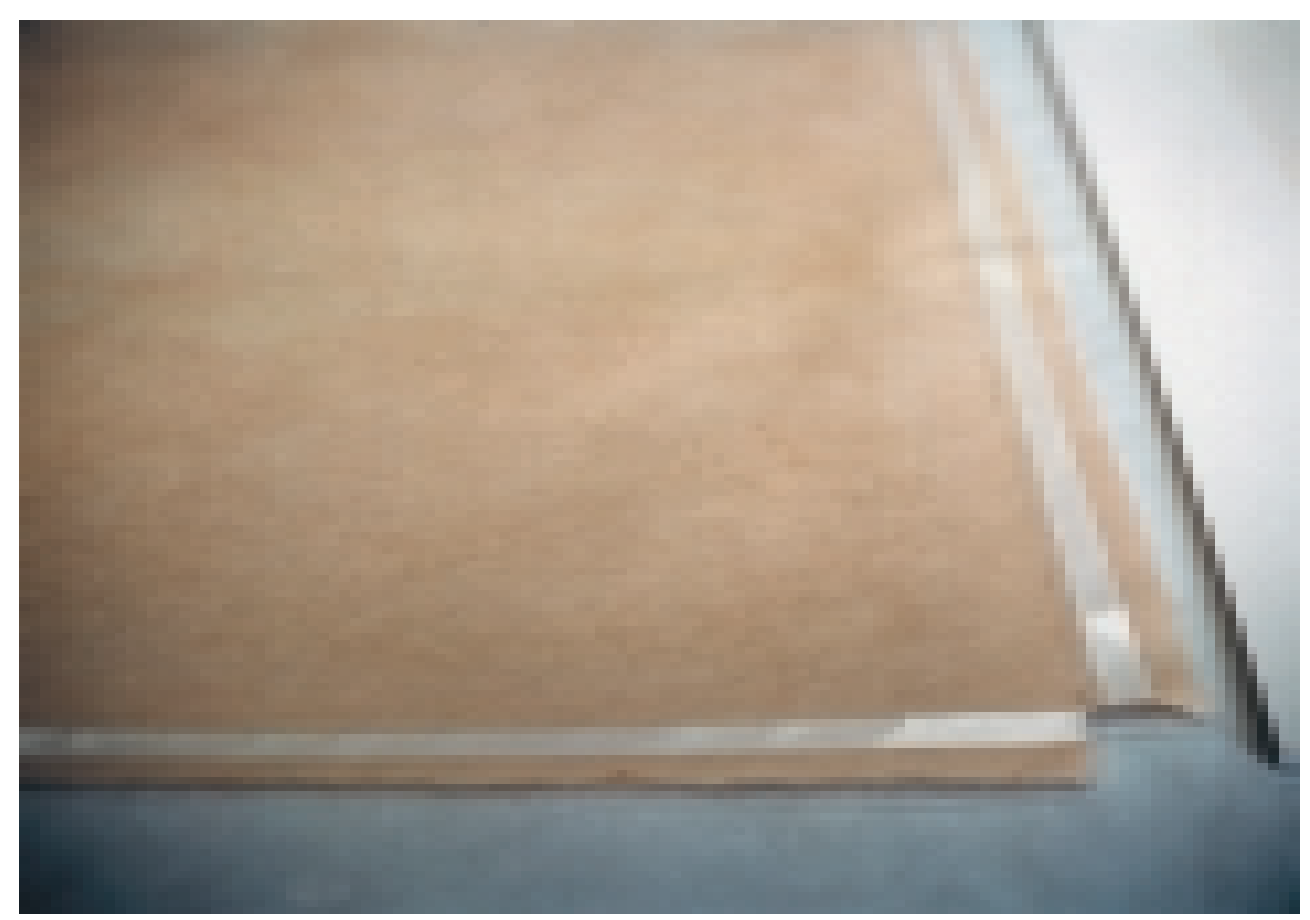

FIGURA 18 - Aplicação de fita dupla face nas bordas do papel japonês para fixação da fotografia no display board. Fotografia de José Rosael. 


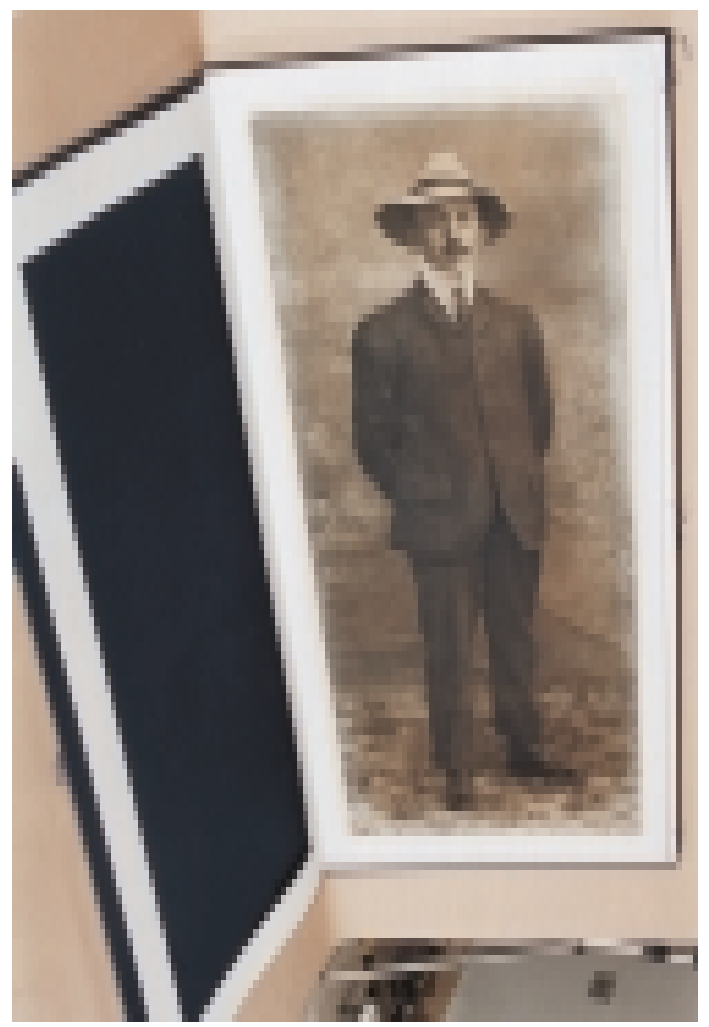

FIGURA 19 - Fotografia restaurada, na caixa com o passe-partout levantado. Fotografia de José Rosael.

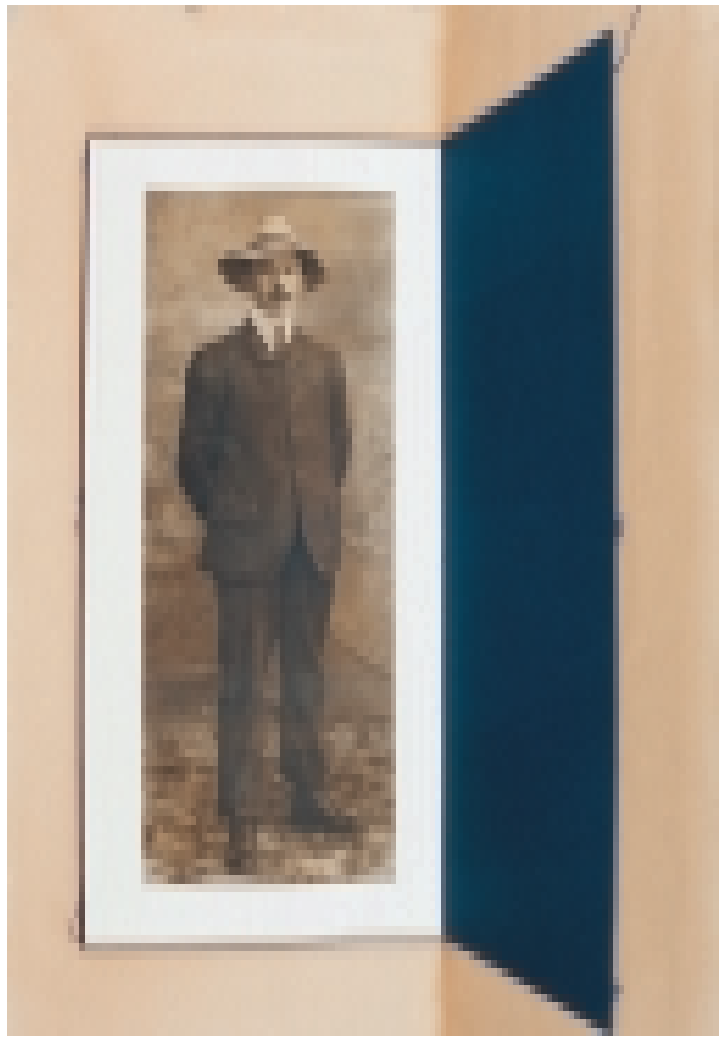




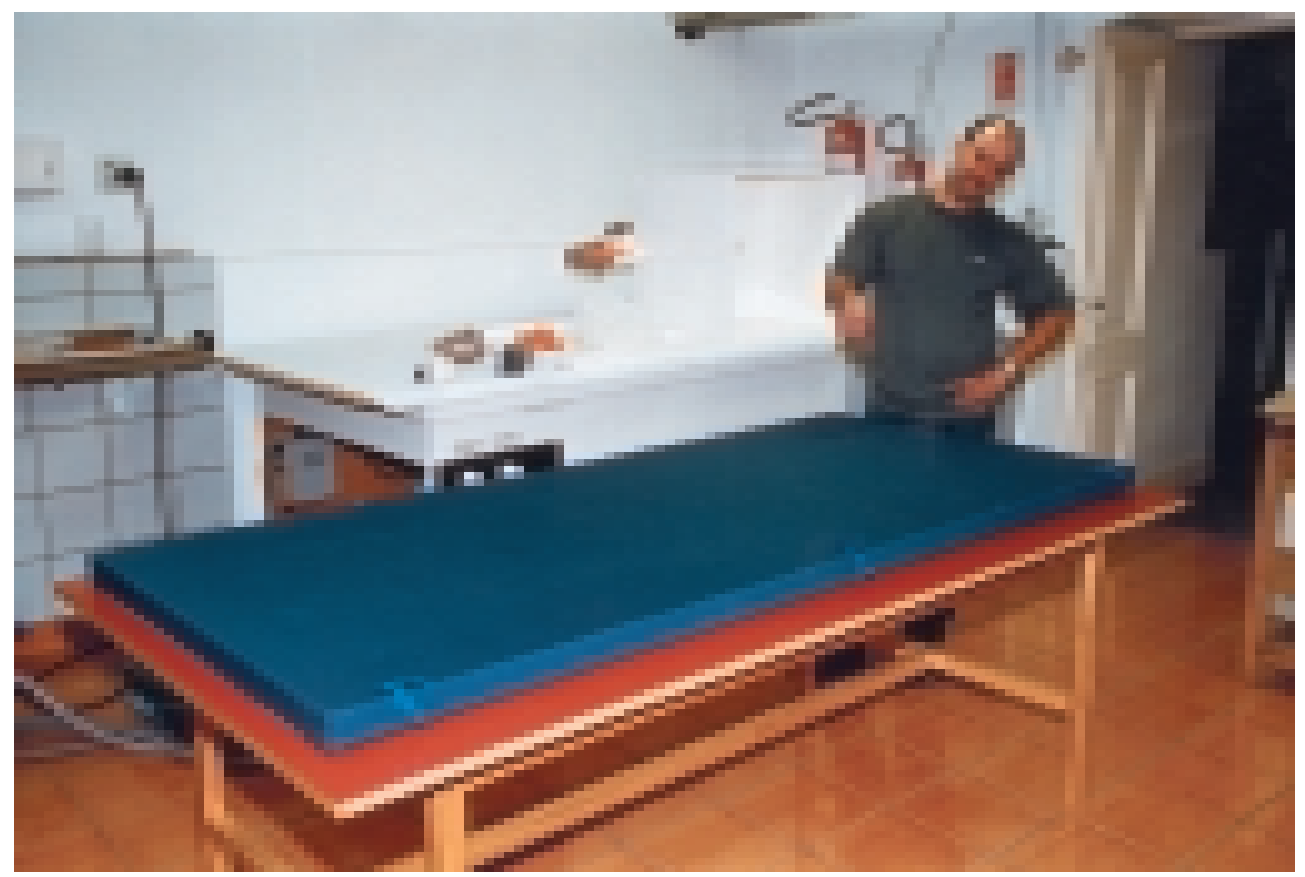

FIGURA 21 - Embalagem fechada. Fotografia de José Rosael.

Se num caso extremo fosse preciso recuperar informações ou indispensável a sua exposição, recorreríamos, com certeza, à reprodução digital com grandes vantagens, evitando-se a restauração e preservando-se o original.

A grande extensão da intervenção realizada, indispensável para sua preservação futura, não deve ser tomada como modelo ou como parâmetro para novas aplicações. Cada intervenção é sempre um estudo de caso, um trabalho único definido por um conjunto de características materiais e pelo estado de conservação, e norteada pelos critérios adotados na instituição.

O conservador/restaurador deve investir cada vez mais na conscientização de todos os profissionais envolvidos na pesquisa, guarda e exposição de acervo fotográfico, no que diz respeito ao amplo campo de conhecimento da Conservação Preventiva, evitando-se tanto quanto possível uma intervenção de restauração.

\section{REFERÊNCIAS}

BARBUY, Heloisa (Coord.). Dossiê: coleção Santos Dumont. São Paulo: Museu Paulista da USP, 2000 (ms).

BARUKI, Sandra; SARAMAGO,Ana. Projeto de Conservação de Acervo Fotográfico de Pierre Verger. In: CONGRESSO ABRACOR, 9., 1998, Bahia. Anais....

BURGI, Sérgio.Introdução à preservação e conservação de acervos fotográficos: técnicas, métodos e materiais. Rio de Janeiro: INFoto/FUNARTE, 1985. 2. ed.em 1988. 


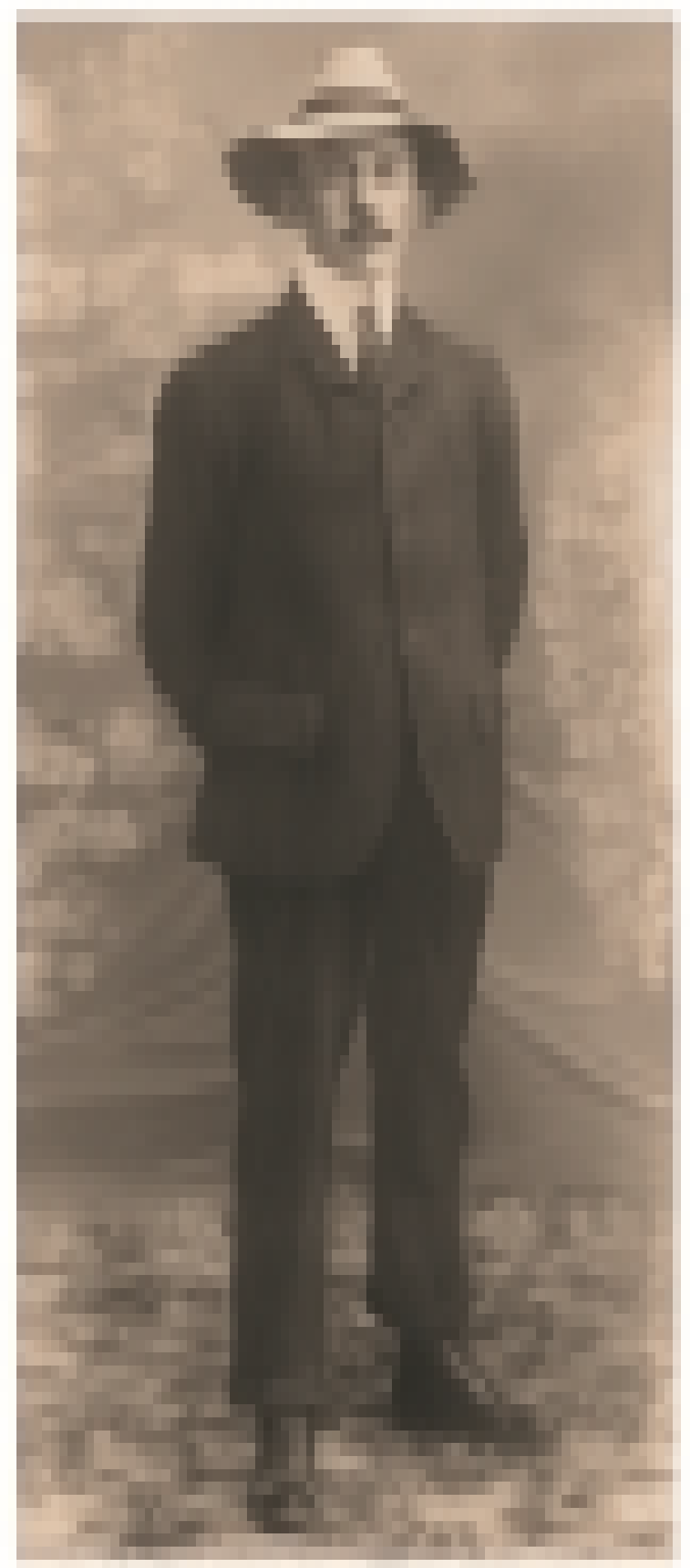

FIGURA 22 - Fotografia após restauração digital, impressa em papel fotográfico. Fotografia digital de Beatriz Carvalho Ricardo. 
BURGI, Sérgio.A preservação dos materiais fotográficos: o processamento para permanência.Revista Fotóptica, São Paulo, n. 120, p. 2, 42, 45, [s.d.].

EASTMAN KODAK CO. Preservação e remoção do mofo de filmes revelados. São Paulo: Kodak, [s.d.].

KOSSOY, Boris. Dicionário bistórico-fotográfico brasileiro: fotógrafos e ofício da fotografia no Brasil (1833-1910). São Paulo: Instituto Moreira Salles, 2002.

KOSSOY, Boris. O Papel do MIS na preservação do patrimônio cultural brasileiro. In: MUSEU da Imagem e Som/ Encontro de Fotografia e Memória Nacional. São Paulo:Secretaria da Cultura, 1981. p. $157-167$.

MELLO, Márcia; PESSOA, Maristela. Manual de acondicionamento de materia fotográfico. Rio de Janeiro: FUNARTE/IBAC, 1994.

OLIVEIRA, João Sócrates de. Manual prático de preservação fotográfica. São Paulo: Museu da Indústria, Comércio e Tecnologia de São Paulo, 1980. (Museus \& Técnicas, p.5).

PAVÃO, Luís. Conservação de coleções de fotografia. Lisboa: Dinalivro, 1997.

PAVÃO, Luís. Dicionário e glossário de termos usados em conservação fotográfica. Lisboa: Fundação Calouste Gulbenkian, 1990.

PIMSTEIN, Ilonka Csillag. Conservación, Fotografia Patrimonial. Chile: Centro Nacional del Patrimonio Fotografico, 2000.

REILLY, James M. Care and Identification of the 19th Century Photografic Prints. Rochester: Kodak Publications, 1986.

TAUNAY,Affonso de E. Guia da secção bistorica do Museu Paulista. São Paulo: Imprensa Official do Estado, 1937.

Artigo apresentado em 8/2003. Aprovado em 9/2003. 
Restauração da fotopintura em tamanho natural de Santos Dumont por Giovanni Sarracino

Yara Lígia Mello Moreira Petrella

Nazareth Coury

Sônia Maria Spigolon

Beatriz Carvalho Ricardo

Trata-se da apresentação dos procedimentos relativos à restauração da fotopintura em tamanho natural de Santos Dumont, feita pelo fotógrafo Giovanni Sarracino. Discute-se todas as fases que abragem desde o diagnóstico, critérios, definição de metodologias de recuperação até a reprodução e tratamento digitalizado da imagem.

PALAVRAS-CHAVE: Fotopintura. Conservação. Restauração digital.

Anais do Museu Paulista. São Paulo. N. Sér.v. 6/7.p. 161-180 (1998-1999). Editado em 2003.

Santos Dumont's natural-sized photo painting restoration by Giovanni Sarracino

Yara Lígia Mello Moreira Petrella

Nazareth Coury

Sônia Maria Spigolon

Beatriz Carvalho Ricardo

It is about the procedures concerning Santos Dumont's natural-sized photo painting restoration, made by the photographer Giovanni Sarracino. All the phases that comprehend from the diagnosis, criteria, definition and restoration methodologies to the reproduction and image-digitalized treatment are discussed.

KEYWORDS: Photo painting. Conservation. Digital Restoration.

Anais do Museu Paulista. São Paulo. N. Sér.v. 6/7. p. 161-180 (1998-1999). Editado em 2003.

Uma História da História da Fotografia

Ricardo Mendes

O ensaio aborda a constituição do campo da pesquisa sobre a fotografia no Brasil, com destaque para o segmento da história da fotografia a partir da década de 1970. A análise procura identificar os principais agentes (pesquisadores, entidades e programas institucionais) e detectar suas interações segundo uma primeira proposta de periodização sobre o tema.

PALAVRAS-CHAVE: Fotografia. História da fotografia. Fotografia brasileira. Historiografia

Anais do Museu Paulista. São Paulo. N. Sér.v. 6/7. p. 183-205 (1998-1999). Editado em 2003.

A story of the History of Photography

Ricardo Mendes

The essay examines the constitution of Brazil's photography research field, with prominence to the segment of History of Photography, starting from the decade of 1970. The analysis tries to identify the main agents (researchers, entities and institutional programs) and detect their interactions according to a first periodization proposal on the subject.

KEYWORDS: Photography, History of Photography, Brazilian Photography, historiography. Anais do Museu Paulista. São Paulo. N. Sér.v. 6/7.p. 183-205 (1998-1999). Editado em 2003

Um balanço bibliográfico e de fontes da estereoscopia

\section{Gavin Adams}

O balanço bibliográfico que se segue é uma reflexão acerca da organização de títulos que tratam da estereoscopia. Menos do que uma tentativa de listar todos os títulos disponíveis em uma bibliografia completa, a presente reflexão quer mapear os tipos principais de publicação de interesse estereoscópico encontrados no curso de sua pesquisa de doutorado. Ademais, o presente balanço quer oferecer uma meditação sobre algumas das particularidades e incidências da bibliografia encontrada, de modo a oferecer ao pesquisador da estereoscopia um guia inicial para seus trabalhos. 